\title{
Adverse factors and postoperative neuropathic pain in challenging video-assisted thoracoscopic surgery
}

\author{
Takahiro Homma ${ }^{1,2}$, Yoshifumi Shimada ${ }^{1}$, Keitaro Tanabe ${ }^{1}$, Yushi Akemoto ${ }^{1}$, Toshihiro Ojima ${ }^{2}$, \\ Yutaka Yamamoto $^{2}$, Naoya Kitamura ${ }^{2}$, Naoki Yoshimura ${ }^{1}$ \\ ${ }^{1}$ Department of General Thoracic and Cardiovascular Surgery, Graduate School of Medicine and Pharmaceutical Sciences, University of Toyama, \\ Toyama, Japan; ${ }^{2}$ Division of Thoracic Surgery, Joetsu General Hospital, Niigata, Japan \\ Contributions: (I) Conception and design: T Homma; (II) Administrative support: T Homma, N Yoshimura; (III) Provision of study materials or \\ patients: All authors; (IV) Collection and assembly of data: All authors; (V) Data analysis and interpretation: T Homma; (VI) Manuscript writing: All \\ authors; (VII) Final approval of manuscript: All authors. \\ Correspondence to: Takahiro Homma. Department of General Thoracic and Cardiovascular Surgery, Graduate School of Medicine and Pharmaceutical \\ Sciences, University of Toyama, 2630 Sugitani, Toyama, 930-0194, Japan. Email: hommat@med.u-toyama.ac.jp.
}

\begin{abstract}
Background: Whether challenging video-assisted thoracoscopic surgery (VATS) is a minimal invasive surgery remains controversial. This study aimed to analyze causes of challenging conventional multiple-port VATS (CVATS) and conversion to thoracotomy and postoperative pain to provide indications for VATS.

Methods: This was a two-center retrospective study. Challenging VATS was defined as CVATS with operation time $\geq 5$ hours and it was converted to thoracotomy. This study included patients who were admitted to Joetsu General Hospital (Joetsu, Niigata, Japan) and Toyama University Hospital (Toyama, Japan) for elective CVATS between April 2013 and March 2019. The exclusion criteria were as follows: a planned thoracotomy, uniportal VATS, robot-assisted thoracoscopic surgery, and simultaneous resection of extrathoracic organs.
\end{abstract}

Results: A total of 911 (91.6\%) patients underwent CVATS. Of these cases, 876 (96.2\%) were suitable VATS cases. On the contrary, 35 cases $(3.8 \%)$ were recognized as challenging VATS. In $21(2.3 \%)$ cases, VATS took $\geq 5$ hours, and $14(1.5 \%)$ VATS cases were converted to thoracotomy. The causes were severe adhesions $(62.9 \%)$, air leak (45.7\%), body position changes (22.9\%), large tumor $(14.3 \%)$, bronchoplasty or angioplasty (8.6\%), and bleeding (2.9\%). The minimum diameter of large tumors was $61.4 \mathrm{~mm}(53-67 \mathrm{~mm})$. In 15 (71.4\%) patients, VATS took $\geq 5$ hours, and 10 (71.4\%) patients who were converted to thoracotomy developed postoperative neuropathic pain.

Conclusions: In this study, VATS $\geq 5$ hours and conversion from VATS to thoracotomy were complicated by postoperative neuropathic pain. In case of bronchoplasty, angioplasty, and large tumor with minimum diameter $\geq 5 \mathrm{~cm}$, a thoracotomy approach would be appropriate depending on the skill and experience of the surgeon. In cases of local or vascular sheath adhesion, if operation progress is delayed, it may be necessary to set a time limit and decide to convert to thoracotomy, considering patient's safety first.

Keywords: Thoracic surgery; video-assisted thoracoscopic surgery; thoracotomy; neuropathic pain; adhesions

Submitted Aug 27, 2020. Accepted for publication Dec 18, 2020.

doi: 10.21037/apm-20-1729

View this article at: http://dx.doi.org/10.21037/apm-20-1729

\section{Introduction}

Video-assisted thoracoscopic surgery (VATS) is major surgical technique for lung disorders worldwide, and more minimally invasive VATS approaches such as uniportal VATS, robot-assisted thoracoscopic surgery, and needlescopic surgery, have been developing and widely spreading $(1,2)$. In addition, complicated VATS procedures such as bronchoplasty and angioplasty have been recently 
reported (3). As the indications for VATS are expanding, the indications for thoracotomy are becoming unclear. The purpose must not only to perform thoracoscopic procedures but also to cure the disease. With our extensive experience in performing VATS, we thought about the indications of a new thoracoscopic surgery and whether longer thoracoscopic surgery is minimally invasive, that is, which is less invasive, longer VATS or shorter thoracotomy?

Development of minimally invasive approaches in thoracic surgery is one of causes for postoperative neuropathic pain. We previously reported that risk factors for neuropathic pain were preoperative use of hypnotic medication, thoracotomy, and duration of surgery $\geq 2.5$ hours, and VATS was a negative association with postoperative neuropathic pain (4). Pregabalin (50 mg/day) had a significant preventive effect on postoperative neuropathic pain after thoracic surgery (5). Nevertheless, $19.6 \%$ of patients had postoperative neuropathic pain (5). Longer VATS could be a risk factor for postoperative neuropathic pain, even with pregabalin, because duration of surgery $\geq 2.5$ hours was also a significant factor in thoracotomy (4). That is, although minimally invasive surgery is often discussed only by the size or number of incisions, operation time is also an important factor. Previous reports have focused on the comparison of surgical approaches and have not adequately discussed the time effect. In particular, the frequency of neuropathic pain in patients who underwent VATS for a long period and conversion to thoracotomy transition was an issue related to this study. It is also necessary to examine the factors that lead to the requirement of VATS for a long period and conversion to thoracotomy in the era when even highly difficult surgery can be performed under VATS. True thoracotomy indications may give benefits to patients.

In this study, we aimed to analyze postoperative neuropathic pain and causes of a prolonged conventional multiple-port VATS (CVATS) and conversion to thoracotomy and to provide indications suitable for VATS.

We present the following article in accordance with the STROBE reporting checklist (available at http://dx.doi. org/10.21037/apm-20-1729).

\section{Methods}

\section{Study design and patients}

The study was conducted in accordance with the Declaration of Helsinki (as revised in 2013). This two-center retrospective study was approved by the Ethics Committee of Joetsu General Hospital with a waiver of informed consent due to its retrospective design (J-191). This study included all patients who were admitted to Joetsu General Hospital (Joetsu, Niigata, Japan) and Toyama University Hospital (Toyama, Japan) for elective CVATS between April 2013 and March 2019. The exclusion criteria were as follows: planned thoracotomy, uniportal VATS, robotassisted thoracoscopic surgery, simultaneous resection of extrathoracic organs, and past or current neuropathic pain. Long-time surgery began on day time. No elective surgery was performed at night except for emergency surgery. All procedures were performed by one chief surgeon and five residents. The chief surgeon has been accredited by the Japanese Board of General Thoracic Surgery, worked at the two hospitals, and was involved in deciding on the surgical indication. The overall responsibility for the quality of all the procedures for a given patients was controlled by the chief surgeon in accordance with sufficient quality requirements. All treatment plans were finalized by the chief surgeon. The chief surgeon gave instructions if a resident was behind in the procedure, and if that did not proceed in the same scene, the chief surgeon performed the operation instead. Also, if the chief surgeon judged that the procedure was very dangerous, the surgeon was replaced by the chief surgeon.

\section{Definition of challenging VATS}

Challenging VATS was defined as a CVATS with operation time longer than 5 hours and it was converted to thoracotomy. Challenging VATS cases were analyzed based on operation records, anesthesia records, and surgical videos. The reasons of challenging VATS were specified in the operation record or anesthesia record. If the reason was not identified, they were elucidated by observing more than $30 \mathrm{~min}$ of the surgical video.

\section{Preoperative imaging test}

In all cases, a simple chest $\mathrm{X}$-rays and Computed tomography $(\mathrm{CT})$ were performed before surgery. In the case of malignant tumors, contrast-enhanced CT, cerebral magnetic resonance imaging, and positron emission tomography were also performed unless renal dysfunction with eGFR $<50 \mathrm{~mL} / \mathrm{min}$ or uncontrolled diabetes.

\section{Surgical procedure}

General anesthesia was maintained using single-lung 
ventilation with a double-lumen endotracheal tube. Patients were placed in the lateral decubitus position. The surgical approach first involved CVATS. Patients requiring partial lung resection, including bullectomy, underwent three-port VATS with two $5-\mathrm{mm}$ ports and one 10 -mm port. For lobectomy and segmentectomy, an additional $5-\mathrm{mm}$ port was used. Segmentectomy was performed for $\mathrm{cN} 0$ lung cancer of $2 \mathrm{~cm}$ or less, with ground glass opacity type.

For tumor size larger than $5 \mathrm{~cm}$, a subxiphoid incision was performed for delivery of the resected specimen (6). When a subxiphoid incision was needed, the incision was immediately performed after resection of the specimen in the hemilateral decubitus position. After the specimen was delivered, the patient was returned to the lateral decubitus position and the intrathoracic operation was resumed. The subxiphoid wound was sutured in the supine position after the intrathoracic operation completion.

For air leaks, an intraoperative sealing test was routinely performed. If air leaks were detected, the fibrin glue plus poly glycolic acid sheet and/or free pericardial fat pad suturing were performed $(7,8)$. Free pericardial fat pad suturing was carried out, when moderate to severe air leaks were detected. If severe air leak was continued after the supine position or after extubation despite these procedures, the patient was returned to the lateral position and then the above procedure was repeated.

A total of six surgeons performed the surgeries. Complicated or bogged surgeries were performed by the chief surgeon or converted to thoracotomy. A 20-Fr chest tube was inserted at the end of the procedure.

\section{Pain management}

In the standard pain management, all patients received epidural analgesia and oral drugs. Patients received loxoprofen $180 \mathrm{mg} /$ day from the first postoperative day and $25 \mathrm{mg}$ pregabalin twice daily from the second postoperative day for 3 months (5). In patients with an estimated glomerular filtration rate (eGFR) of $<50 \mathrm{~mL} / \mathrm{min}$, $1,200 \mathrm{mg} /$ day acetaminophen was prescribed. The medication was continued until pain-free status was achieved.

Thoracic epidural catheterization was usually performed prior to induction at the T4-5, T5-6, or T6-7 intervertebral space using a loss-of-resistance technique. Catheter placement was confirmed with a test dose of $4 \mathrm{~mL}$ of $1 \%$ lidocaine. The epidural infusion was initiated before surgery in the operating room. The drug combination was administered as continuous infusions of $2.0 \mathrm{mg} / \mathrm{mL}$ of ropivacaine and $2.5 \mu \mathrm{g} / \mathrm{mL}$ of fentanyl. The infusion rate was adjusted to $2-4 \mathrm{~mL} / \mathrm{h}$. Epidural analgesia was discontinued the next day, after chest tube removal. Intravenous fentanyl was administered to patients with contraindications for epidural anesthesia, such as prolonged coagulation time, or patients who declined epidural anesthesia. Intravenous fentanyl was started in the operating room. The fentanyl infusion ratie was adjusted to between 0.01 and $0.04 \mathrm{mg} / \mathrm{h}$.

\section{Inclusion criteria for patients with neuropathic pain}

Neuropathic pain is defined as "pain caused by a lesion or disease of the somatosensory system" (9). We used validated neuropathic pain screening tools the Leeds Assessment of Neuropathic Symptoms and Signs and the related selfcompleted version (S-LANSS) to ensure consistency and reduce missing data between assessments during the acute and follow-up periods $(10,11)$. The S-LANSS score is an evaluation method to identify pain of predominantly origin, as distinct from no nociceptive pain, without the need for clinical examination. A total score of 12 or higher is evaluated as suggesting pain of predominantly neuropathic origin. We routinely used the S-LANSS score to evaluate postoperative neuropathic pain. Chronic pain was defined as pain that continued for more than 3 months after surgery.

\section{Variables and assessments}

The following patient and surgical characteristics and follow-up parameters were recorded: age, sex, past medical history, body mass index, diagnosis, diseased side, intraoperative bleeding, operation duration, chest tube duration, complications (prolonged air leak defined as an air leak lasting $>5$ days), postoperative neuropathic pain (intractable neuropathic pain was defined as pain that needed analgesics therapy for over 1 year), and duration of postoperative hospitalization. A complication was defined as any deviation from the normal postoperative course and graded according to the Clavien-Dindo classification (12).

\section{Data management and statistical analysis}

This is a retrospective study of data collected in the University of Toyama and the Joetsu General Hospital. Collected data included operation records, anesthesia records, surgical videos, and neuropathic pain. A patient 


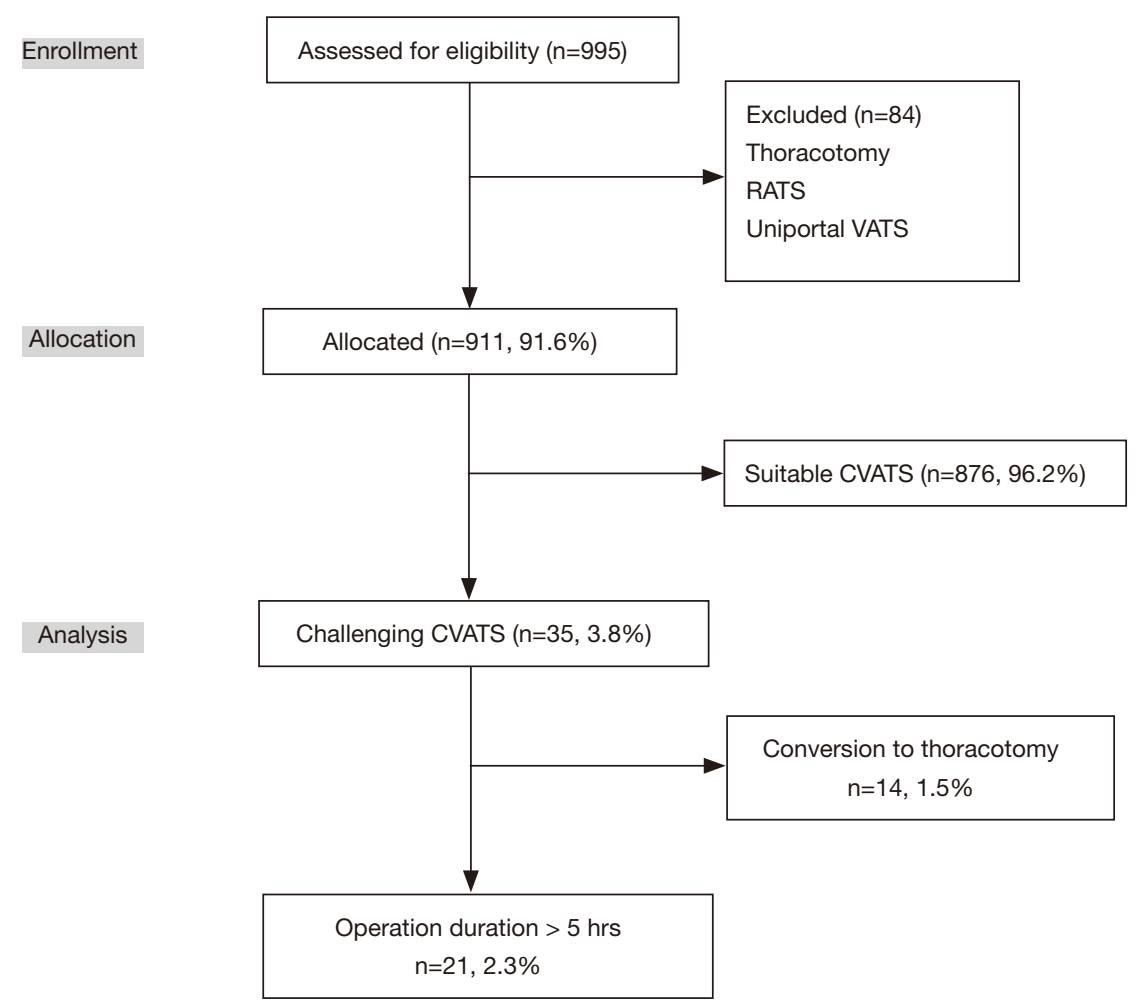

Figure 1 Patient selection flowchart. CVATS, conventional multiple-port video-assisted thoracoscopic surgery; RATS, robot-assisted thoracic surgery.

with missing data were excluded from analyses.

For univariate analysis, inter-group differences were evaluated using the non-parametric Wilcoxon rank-sum test. The $\chi^{2}$ or Fisher's exact test was used to compare categorical variables when necessary. Significance was defined as $\mathrm{P}<0.05$. All reported $\mathrm{P}$ values were two-sided. Continuous variables were presented as mean \pm standard deviation for normally distributed data and median with interquartile range for non-normally distributed data. Categorical variables were presented as n (\%). All statistical analyses were performed using JMP version 12.0 (SAS Institute, Inc., Cary, NC, USA).

\section{Results}

In total, 995 patients were assessed for eligibility, 84 (8.4\%) of whom were excluded after the application of exclusion criteria. A total of 911 (91.6\%) patients underwent CVATS (Figure 1). Of these, 876 (96.2\%) were suitable VATS cases. On the contrary, 35 cases $(3.8 \%)$ were recognized as challenging VATS. In addition, 21 (2.3\%) cases took $\geq 5$ hours and $14(1.5 \%)$ cases were converted to thoracotomy. No patient was missed and lost the data. The number of patients who experienced postoperative neuropathic pain was significantly higher in the challenging VATS group than the suitable VATS group $(71.4 \%$ vs. $22.0 \% ; \mathrm{P}<0.0001)$. There were no significant differences between VATS for $\geq 5$ hours group and conversion to thoracotomy group in the following measured variables: postoperative neuropathic pain $(71.4 \%$ vs. $71.4 \% ; \mathrm{P}=1.00)$ and intractable pain (9.5\% vs. $21.4 \% ; \mathrm{P}=0.37)$.

The background factors of 21 patients who underwent VATS for $\geq 5$ hours are summarized in Table 1 . The median age was 59 years, 17 (80.9\%) patients were male, and preoperative diagnoses were lung cancer $(n=15$, $71.4 \%)$, mediastinal tumor $(n=4,19.0 \%)$, non-tuberculous mycobacteriosis $(n=1,4.8 \%)$, and esophagobronchial fistula ( $n=1,4.8 \%)$. Surgical procedures performed were lobectomy in 10 patients, segmentectomy in 6 patients, mediastinal tumor resection in 4 patients, and esophagobronchial fistula closure in the other. The median operation duration was 340 (range, 303-499) min, the median intraoperative blood loss volume was 150 (IQR, 50-270) $\mathrm{mL}$, and the total complication rate was $42.9 \%$, and the details were as follows: 
Table 1 Operation duration $\geq 5$ hours

\begin{tabular}{|c|c|}
\hline Variables & $\begin{array}{l}\text { Outcome }(\mathrm{n}=21) \\
\mathrm{n}(\%)\end{array}$ \\
\hline Age, median [range] & 59 [8-78] \\
\hline Man & $17(80.9)$ \\
\hline BMI $\left(\mathrm{kg} / \mathrm{m}^{2}\right)$, average $\pm \mathrm{SD}$ & $21.9 \pm 2.8$ \\
\hline \multicolumn{2}{|l|}{ Preoperative diagnosis } \\
\hline Lung cancer & $15(71.4)$ \\
\hline Mediastinal tumor & $4(19.0)$ \\
\hline Non-tuberculous mycobacteriosis & $1(4.8)$ \\
\hline Esophagobronchial fistula & $1(4.8)$ \\
\hline \multicolumn{2}{|l|}{ Procedure } \\
\hline Lobectomy & $10(47.6)$ \\
\hline Segmentectomy & $6(28.6)$ \\
\hline Mediastinal tumor resection & $4(19.0)$ \\
\hline Esophagobronchial fistula closure & $1(4.8)$ \\
\hline Complete planned procedure & $21(100.0)$ \\
\hline Intraoperative bleeding (g), median [IQR] & $150(50-270)$ \\
\hline Operation duration (min), median (range) & 340 (303-499) \\
\hline Chest tube duration (day), median [IQR] & $2[2.0-5.5]$ \\
\hline \multicolumn{2}{|l|}{ Complications } \\
\hline Total & $9(42.9)$ \\
\hline Prolonged air leak (>5 days) & $4(19.0)$ \\
\hline Pneumonia & $2(9.5)$ \\
\hline Arrhythmia & $1(4.8)$ \\
\hline Delirium & $1(4.8)$ \\
\hline ARDS & $1(4.8)$ \\
\hline Postoperative neuropathic pain & $15(71.4)$ \\
\hline Intractable neuropathic pain & $2(9.5)$ \\
\hline $\begin{array}{l}\text { Postoperative hospitalization (day), median } \\
\text { [IQR] }\end{array}$ & $8[5.5-11.5]$ \\
\hline \multicolumn{2}{|l|}{ Adverse factor* } \\
\hline Air leak & $16(76.2)$ \\
\hline Intraoperative & $12(75.0)$ \\
\hline After extubation & $4(25.0)$ \\
\hline Severe adhesions & $13(61.9)$ \\
\hline Local & $8(61.5)$ \\
\hline Whole thoracic cavity & $5(38.5)$ \\
\hline Body position changes & $8(38.1)$ \\
\hline Large tumor & $3(14.3)$ \\
\hline
\end{tabular}

*, overlapping. ARDS, acute respiratory distress syndrome; BMI, body mass index; IQR, interquartile range; SD, standard deviation. prolonged air leak ( $>5$ days) $(\mathrm{n}=4,19.0 \%)$, pneumonia $(\mathrm{n}=2$, 9.5\%), arrhythmia, delirium, and acute respiratory distress syndrome (ARDS) (each $\mathrm{n}=1,4.8 \%$ ). The median hospital stay was 8 (IQR, 5.5-11.5) days. Fifteen (71.4\%) patients reported postoperative neuropathic pain, of which two patients $(9.5 \%)$ developed intractable neuropathic pain. Adverse factors were classified into air leaks, adhesions, body position changes, and visual field difficulties due to tumors. Sixteen events of air leaks were recorded, of which 12 occurred during surgery and four occurred after extubation. All four cases of air leak after extubation were complicated by neuropathic pain, but there were no cases of intractable pain. Adhesions were subdivided into local advanced adhesions $(n=8)$ and adhesions of the whole thoracic cavity $(\mathrm{n}=5)$.

Clinical data of 14 VATS cases converted to thoracotomy are summarized in Table 2. The median patient age was 74 years, $85.7 \%$ were male, and all patients had preoperative diagnosis of lung cancer. The median operation duration was 347 (range, 204-420) min, median intraoperative blood loss volume was 285.5 (IQR, 198.8-513.3) mL, and the complication rate was $57.1 \%$. The decision time for the conversion to thoracotomy was 109 (range, 42-237) $\mathrm{min}$. The procedures were lobectomy $(\mathrm{n}=10)$, lung segmentectomy $(\mathrm{n}=3)$, and partial resection $(\mathrm{n}=1)$. Thirteen patients $(92.9 \%)$ completed the procedure on schedule, except for one patient who underwent partial resection, in which partial resection was performed due to surgical difficulty caused by high hilar adhesion, but the final pathological diagnosis was inflammatory pseudotumor. The total complication rate was $57.1 \%$, and the details were as follows: prolonged air leak ( $>5$ days) $(n=4,28.6 \%)$, arrhythmia $(\mathrm{n}=2,14.3 \%)$, delirium, ARDS, atelectasis, and transient ischemic attack (each $\mathrm{n}=1,7.1 \%$ ). The duration of hospital stay was 10 (IQR, 9.8-14.3) days. Ten patients (71.4\%) reported postoperative neuropathic pain, of which three patients $(21.4 \%)$ developed intractable neuropathic pain. Adverse factors were categorized into adhesions, visual field difficulties due to tumors, bronchoplasty, and bleeding. Adhesions were further subdivided into vascular sheath adhesions (3 cases) and adhesions of the whole thoracic cavity (6 cases).

Causes of challenging VATS are summarized in Table 3. Briefly, they were severe adhesions (62.9\%), air leak (45.7\%), body position changes (22.9\%), large tumor (14.3\%), bronchoplasty or angioplasty $(8.6 \%)$, and bleeding $(2.9 \%)$. The minimum diameter of large tumors was 61.4 (range, 53-67) mm (Table 4). 
Table 2 Conversion to thoracotomy

\begin{tabular}{|c|c|}
\hline Variables & $\begin{array}{l}\text { Outcome }(n=14) \\
n(\%)\end{array}$ \\
\hline Age, median [range] & $74[64-80]$ \\
\hline Man & $12(85.7)$ \\
\hline BMI $\left(\mathrm{kg} / \mathrm{m}^{2}\right)$, mean $\pm \mathrm{SD}$ & $25.4 \pm 4.2$ \\
\hline \multicolumn{2}{|l|}{ Preoperative diagnosis } \\
\hline Lung cancer ${ }^{\star}$ & $14(100.0)$ \\
\hline \multicolumn{2}{|l|}{ Procedure } \\
\hline Lobectomy & $10(71.4)$ \\
\hline Segmentectomy & $3(21.4)$ \\
\hline Partial resection* & $1(7.1)$ \\
\hline Complete planned procedure & $13(92.9)$ \\
\hline Intraoperative bleeding (g), median [IQR] & 285.5 [198.8-513.3] \\
\hline Operation duration (min), median (range) & 347 [204-420] \\
\hline Conversion time (min), median (range) & 109 [42-237] \\
\hline Chest tube duration (day), median [range] & $2[1.0-5.5]$ \\
\hline \multicolumn{2}{|l|}{ Complications } \\
\hline Total & $8(57.1)$ \\
\hline Prolonged air leak ( $>5$ days) & $4(28.6)$ \\
\hline Arrhythmia & $2(14.3)$ \\
\hline Delirium & $1(7.1)$ \\
\hline ARDS & $1(7.1)$ \\
\hline Atelectasis & $1(7.1)$ \\
\hline TIA & $1(7.1)$ \\
\hline Postoperative neuropathic pain & $10(71.4)$ \\
\hline Intractable neuropathic pain & $3(21.4)$ \\
\hline $\begin{array}{l}\text { Postoperative hospitalization (day), } \\
\text { median [IQR] }\end{array}$ & $10[9.8-14.3]$ \\
\hline \multicolumn{2}{|l|}{ Adverse factor ${ }^{\star \star}$} \\
\hline Severe adhesions & $9(64.3)$ \\
\hline Whole thoracic cavity & $6(66.7)$ \\
\hline Vascular sheath & $3(33.3)$ \\
\hline Bronchoplasty/angioplasty & $3(21.4)$ \\
\hline Large tumor & $2(14.3)$ \\
\hline Bleeding & $1(7.1)$ \\
\hline
\end{tabular}

${ }^{*}$, palliative partial resection was performed for severe hilar adhesions. The final pathological diagnosis was an inflammatory pseudotumor. ${ }^{* *}$, overlapping. ARDS, acute respiratory distress syndrome; BMI, body mass index; IQR, interquartile range; SD, standard deviation; TIA, transient ischemic attack.
Table 3 Challenging VATS factors

\begin{tabular}{lc}
\hline Factors & $\mathrm{n}=35(\%)$ \\
\hline Patient & $22(62.9)$ \\
Severe adhesions & $11(31.4)$ \\
Whole thoracic cavity & $8(22.9)$ \\
$\quad$ Local & $3(8.6)$ \\
Vascular sheath & $16(45.7)$ \\
Air leak & $12(34.3)$ \\
Intraoperative & $4(11.4)$ \\
After extubation & $5(14.3)$ \\
Large tumor (minimum diameter $>5 \mathrm{~cm})$ & \\
Surgeon & $8(22.9)$ \\
Body position changes & $3(8.6)$ \\
Bronchoplasty/angioplasty & $1(2.9)$ \\
Bleeding & \\
\hline
\end{tabular}

VATS, video-assisted thoracoscopic surgery.

Table 4 Large tumor cases

\begin{tabular}{llc}
\hline Case & Classification of difficulty & $\begin{array}{c}\text { Minimum tumor } \\
\text { diameter }(\mathrm{mm})\end{array}$ \\
\hline 1 & Operation duration $>5$ hours & 65 \\
2 & Operation duration $>5$ hours & 55 \\
3 & Operation duration $>5$ hours & 67 \\
4 & Conversion to thoracotomy & 67 \\
5 & Conversion to thoracotomy & 53 \\
Average & & 61.4 \\
\hline
\end{tabular}

\section{Discussion}

In this study, 35 (3.8\%) of 911 cases were recognized as challenging VATS, defined when the operation time was more than 5 hours or VATS converted to thoracotomy. The causes of challenging VATS were severe adhesions, postoperative air leak, poor surgical view and difficulty of extraction due to large tumor, body position changes, bronchoplasty, and bleeding. The former three factors are patient-related factors, and the latter three factors are operator-related factors. Body position changes were dependent on the surgical strategy, and bronchoplasty or angioplasty and bleeding depend on the surgeon skills. For surgeons who have a lot of experience with 
Table 5 Vascular sheath adhesion cases

\begin{tabular}{llllll}
\hline Case & Sex & Age & Disease & Occupational history & Past medical history \\
\hline 1 & Male & 71 & $\begin{array}{l}\text { Lung cancer, } \\
\text { adenocarcinoma, pT1bN0M0 }\end{array}$ & Civil engineering (tunnel) & $\begin{array}{l}\text { Cerebral infarction, Parkinson's disease, } \\
\text { hypertension, hyperlipidemia }\end{array}$ \\
2 & Male & 65 & $\begin{array}{l}\text { Lung cancer, } \\
\text { adenocarcinoma, pT1bN0M0 }\end{array}$ & Sheet metal working & $\begin{array}{l}\text { Colorectal cancer (surgery and chemotherapy), } \\
\text { chronic hepatitis B, hypertension, hyperlipidemia, } \\
\text { hyperuricemia }\end{array}$ \\
3 & Male & 76 & $\begin{array}{l}\text { Lung cancer, squamous cell } \\
\text { carcinoma, pT2aN2M0 }\end{array}$ & Spray coating & $\begin{array}{l}\text { Biliary cancer (surgery and chemotherapy), cerebral } \\
\text { infarction, cardiac infarction, atrial fibrillation, CPFE, } \\
\text { hypertension, hyperlipidemia, hyperuricemia }\end{array}$ \\
\end{tabular}

CPFE, combined pulmonary fibrosis and emphysema.

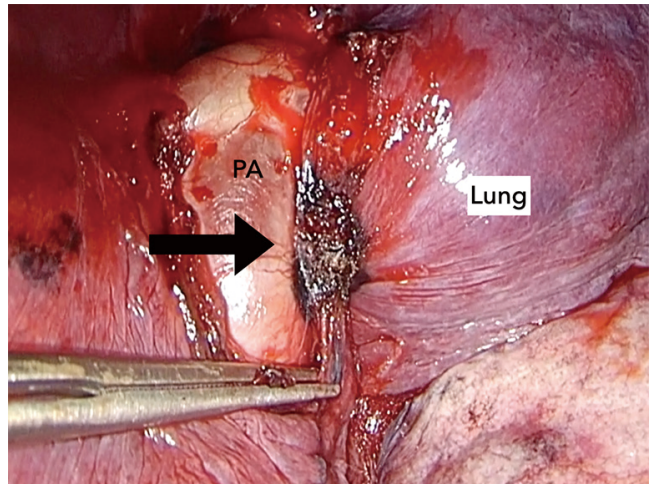

Figure 2 Lymph nodes were firm, with indistinct borders with adjacent organs and radial (black arrow). Suspected effects of pneumoconiosis. Separation between the adventitia and media was difficult. PA, pulmonary artery.

VATS bronchoplasty or angioplasty, these procedures are not necessarily challenging. However, for surgeons with little experience, they are more challenging than thoracotomy. Individual surgeon volume, surgeon age, and surgeon technical skills affected surgical outcome (13-15). Therefore, operator-related factors depend on an institution, but patient-related factors are considered common between institutions.

Severe adhesions were subdivided into three groups depending on the location, whole thoracic cavity, locally invasive, and vascular sheath adhesions. Previously, we reported the usefulness of chest echo predictions for intrathoracic severe adhesions (16). When ultrasound sliding lung sign was absent, severe intrathoracic adhesions could be detected, with a sensitivity of $88.2 \%$, specificity of $100 \%$, positive predictive value of $100 \%$, and negative predictive value of $98.7 \%$. If a patient has severe intrathoracic adhesions, the operation took $78 \mathrm{~min}$ longer and the patient was at risk of more complications, as compared to patients without severe adhesions. Thus, we must reflect on whether VATS approach is better than thoracotomy in severe intrathoracic adhesions cases. In preoperative prediction of local adhesions or invasions, not only chest echo but cine magnetic resonance imaging (MRI) might be useful (17). Cine MRI would be effective in imaging areas not reach by ultrasonography.

In this study, three cases of vascular sheath adhesion were recorded. In this study, three cases of vascular sheath adhesion were recorded (Table 5). Case 1 had rigid intrathoracic lymph nodes (Figure 2). All intrathoracic lymph nodes had similar findings, suggesting pneumoconiosis (18-20). The shape and appearance were amebiform, and the boundaries between the lymph node and pulmonary artery sheath were unclear. The pulmonary artery sheath was located between the adventitia and the media because the lymph nodes soaked into the pulmonary artery sheath. In cases 2 and 3, the border between the lymph nodes and the vascular sheath were viscously adhered (Figure 3). These cases were attributed to chemotherapy for a past cancer. In all cases, thoracoscopic avulsing of the pulmonary artery was difficult and risky; thus, thoracotomy was performed for safety.

Air leak was subdivided into intraoperative leak and postoperative leak immediately after extubation. In all cases, suturing or covering was added to stop the air leak $(21,22)$. In these cases, the patients had emphysema or chronic obstructive pulmonary disease and had high index of prolonged air leak (23). Intraoperative intervention to stop air leak needed longer time (average time $74 \mathrm{~min}$, range 48$148 \mathrm{~min}$ ). However, it is sometimes difficult to stop an air leak by surgical intervention alone. Despite maximum intraoperative treatments, it would be necessary to recognize that intra or postoperative air leaks occur. This is because we 


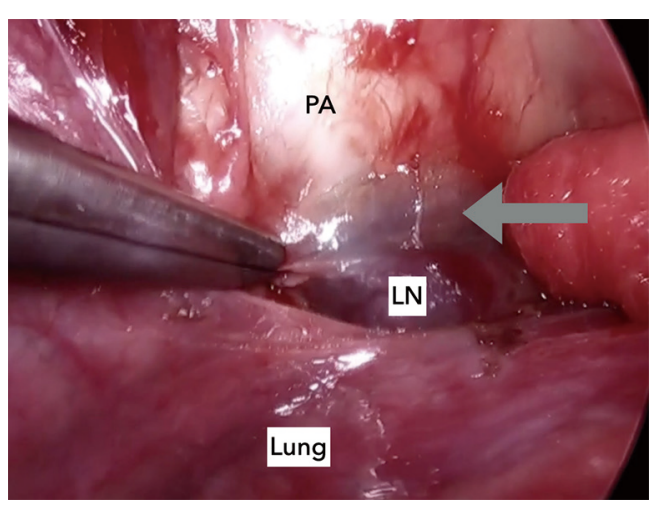

Figure 3 The boundary between the lymph node and the vascular sheath was unclear and adherent (gray arrow). Similar findings were found in all intrathoracic vascular sheaths, not just in one location, suggesting the effect of chemotherapy. PA, pulmonary artery; LN, lymph node.

often experienced the incidence of air leak often decreases due to postural change from a lateral position to a supine position or under spontaneous breathing after extubation.

Moreover, five cases had poor surgical field because of large tumors. Three of the five patients underwent surgery for more than 5 hours, and CVATS in two patients was converted to thoracotomy. The minimum tumor diameter was $61.4 \mathrm{~mm}(53-67 \mathrm{~mm})$. For tumors with minimum diameter of $\geq 5 \mathrm{~cm}$, thoracotomy was suitable because the intercostal space is about one $\mathrm{cm}$, and a certain extract incision would be required for large tumor delivery. Intrathoracic manipulation was possible even with CVATS, but good surgical field would be difficult. In particular, good surgical field around the hilum would be hard to obtain. Therefore, operation duration with thoracotomy might be shorter than CVATS for tumors with minimum diameter of $\geq 5 \mathrm{~cm}$.

The challenging VATS for $\geq 5$ hours cases were significantly more common in one hospital $(4.6 \% v s$. $1.2 \% ; \mathrm{P}=0.0019)$. This was because there were more cases requiring subxiphoid incision than in another hospital. Conversion to thoracotomy were no difference $(1.4 \% v s$. $1.6 \% ; \mathrm{P}=1.00$ ) between two centers.

In this study, the main issue of challenging thoracic surgery would be whether prolonged CVATS is a minimally invasive procedure or whether shorter thoracotomy is invasive. One of the complications of minimally invasive surgery in thoracic surgery is postoperative neuropathic pain. In recent years, a subxiphoid approach had been reported to prevent postoperative neuropathic pain $(24,25)$.
We also added a subxiphoid incision for delivery of the resected specimen of tumor more than $5 \mathrm{~cm} \mathrm{(6).} \mathrm{On} \mathrm{the}$ contrary, we reported that $>2.5 \mathrm{~h}$ operation was one of the risk factors of postoperative neuropathic pain (4). In this study, patients with challenging CVATS more frequently developed postoperative neuropathic pain $(71.4 \%$ vs. $22.0 \%$; $\mathrm{P}<0.0001)$, as compared with the suitable VATS. Even with CVATS approach, long-time surgery was considered a risk factor for postoperative neuropathic pain. Intractable neuropathic pain was not largely common in CVATS, as more cases of challenging CVATS were converted to thoracotomy. Neuropathic pain in patients who underwent CVATS was unlikely to be intractable than in those in whom CVATS was converted to thoracotomy, although there were no significant differences between groups in this study.

Prolonged surgery might be associated with other complications besides neuropathic pain. Prolonged surgery and emergency thoracotomy are stressful not only for the surgeon but also for other medical staffs. Different reasons of stress reduce the surgeon's focus, which may easily lead to accidents. For doctors, increased mental workload was associated with inferior technical performance (26). Emergency care provoked substantial acute stress (27). The incidence of intraoperative complications from VATS pulmonary resection performed during night hours was significantly higher than that from VATS performed during working hours (28). For nurses, $30-40 \%$ of operation room nurses were mentally stressed during surgery. Among scrub nurses, endoscopic surgery was related to their mental stress (29). Excessive long working hours has become a social problem. Long working hours is a risk factor of coronary heart disease and stroke (30). Proper time management is an important aspect for a leadership (31). In cases where surgery requires longer operation time, it may be necessary to secure a short break during surgery to restore concentration (32). Although stress was not evaluated in this study, prolonged surgery, night surgery, and emergency surgery will generally be stressful, not just for nurses, but for everyone as well. Time management should be kept in mind to provide better surgery to patients. The elective surgery should start on day time, and no night surgery should perform except for emergency surgery. There are no nighttime emergency surgery cases in our challenge VATS cases.

\section{Limitation}

This study has several limitations. First, the study has the 
inherent limitations related to its retrospective design and two-center setting. However, the number of 995 cases is not small and is considered to be worth considering. Second, some cases of acceptable CVATS may have adverse factors, but were not included in the analysis. Third, all procedures were performed by one chief surgeon and five residents. The chief surgeon was considered as a control in all cases at the two centers either as a surgeon or a first assistant. That is, adverse factors may depend on the skills of the surgeon and assistant and also, on policies of the facility where the surgery was performed.

\section{Conclusions}

In this study, we found that the causes of challenging VATS or conversion from VATS to thoracotomy were severe adhesions, postoperative air leak, large tumor with minimum diameter of $5 \mathrm{~cm}$ or more, body position changes, bronchoplasty or angioplasty, and bleeding. Whether prolonged VATS is indeed minimal invasive remains controversial. However, challenging VATS and the conversion from VATS to thoracotomy were highly complicated by postoperative neuropathic pain. Thus, short-time thoracotomy might be more minimally invasive than prolonged VATS. In case of bronchoplasty, angioplasty, large tumor with minimum diameter of $5 \mathrm{~cm}$ or more, a thoracotomy approach would be appropriate depending on the skill and experience of the surgeon. In cases of local or vascular sheath adhesion, if operation progress is delayed, it may be necessary to set a time limit and decide to convert to thoracotomy, considering patient's safety first.

\section{Acknowledgments}

We would like to thank Editage (www.editage.com) for English language editing.

Funding: None.

\section{Footnote}

Reporting Checklist: The authors have completed the STROBE reporting checklist. Available at http://dx.doi. org/10.21037/apm-20-1729

Peer Review File: Available at http://dx.doi.org/10.21037/ apm-20-1729

Data Sharing Statement: Available at http://dx.doi. org/10.21037/apm-20-1729

Conflicts of Interest: All authors have completed the ICMJE uniform disclosure form (available at http://dx.doi. org/10.21037/apm-20-1729). The authors have no other conflicts of interest to declare.

Ethical Statement: The authors are accountable for all aspects of the work in ensuring that questions related to the accuracy or integrity of any part of the work are appropriately investigated and resolved. The study was conducted in accordance with the Declaration of Helsinki (as revised in 2013). This two-center retrospective study was approved by the Ethics Committee of Joetsu General Hospital with a waiver of informed consent due to its retrospective design (J-191).

Open Access Statement: This is an Open Access article distributed in accordance with the Creative Commons Attribution-NonCommercial-NoDerivs 4.0 International License (CC BY-NC-ND 4.0), which permits the noncommercial replication and distribution of the article with the strict proviso that no changes or edits are made and the original work is properly cited (including links to both the formal publication through the relevant DOI and the license). See: https://creativecommons.org/licenses/by-nc-nd/4.0/.

\section{References}

1. Sihoe ADL. Uniportal lung cancer surgery: state of the evidence. Ann Thorac Surg 2019;107:962-72.

2. Veronesi G, Novellis P, Voulaz E, et al. Robot-assisted surgery for lung cancer: state of the art and perspectives. Lung Cancer 2016;101:28-34.

3. Tian K, Yang R, Han B. Left upper lobectomy and pulmonary angioplasty by uniportal video-assisted thoracic surgery. J Thorac Dis 2017;9:3269-71.

4. Homma T, Doki Y, Yamamoto Y, et al. Risk factors of neuropathic pain after thoracic surgery. J Thorac Dis 2018;10:2898-907.

5. Homma T, Doki Y, Yamamoto Y, et al. Efficacy of $50 \mathrm{mg}$ pregabalin for prevention of postoperative neuropathic pain after video-assisted thoracoscopic surgery and thoracotomy: a 3-month prospective randomized controlled trial. J Thorac Dis 2019;11:694-701.

6. Doki Y, Ichiki K, Tsuda M, et al. Complete port-accessed lobectomy by the muscle-sparing method. Ann Thorac Surg 2004;77:2230-1. 
7. Kawai H, Harada K, Ohta H, et al. Prevention of alveolar air leakage after video-assisted thoracic surgery: comparison of the efficacy of methods involving the use of fibrin glue. Thorac Cardiovasc Surg 2012; 60:351-5.

8. Ikeda T, Sasaki M, Yamada N, et al. Controlling air leaks using free pericardial fat pads as surgical sealant in pulmonary reception. Ann Thorac Surg 2015;99:1170-5.

9. Jensen TS, Baron R, Haanpaa M, et al. A new definition of neuropathic pain. Pain 2011;152:2204-2205.

10. Bennett $M$. The LANSS Pain Scale: the Leeds assessment of neuropathic symptoms and signs. Pain 2001;92:147-157.

11. Bennett MI, Smith BH, Torrane N, et al. The S-LANSS score for identifying pain of predominantly neuropathic origin: validation for use in clinical and postal research. J Pain 2005;6:149-58.

12. Dindo D, Demartines N, Clavien PA. Classification of surgical complications: a new proposal with evaluation in a cohort of 6336 patients and results of a survey. Ann Surg 2004;240:205-13.

13. Harrison S, Sun T, Kamel MK, et al. Do individual surgeon volumes affect outcomes in thoracic surgery? Eur J Cardiothorac Surg 2019;56:770-7.

14. Tsugawa Y, Jena AB, Orav EJ, et al. Age and sex of surgeons and mortality of older surgical patients: observational study. BMJ 2018;25:361:k1343.

15. Stulber JJ, Huang R, Kreutzer L, et al. Association between surgeon technical skills and patient outcomes. JAMA Surg 2020;155:960-8.

16. Homma T, Ojima T, Yamamoto Y, et al. Utility of the sliding lung sign for the prediction of preoperative intrathoracic adhesions. J Thorac Dis 2020;12:4224-32.

17. Kajiwara N, Akata S, Uchida O, et al. Cine MRI enables better therapeutic planning than CT in cases of possible lung cancer chest wall invasion. Lung Cancer 2010;69:203-8.

18. Enterline PE. A review of mortality data for American coal-miners. Ann N Y Acad Sci 1972;200:260-72.

19. Goldman KP. Mortality of coal-miners from carcinoma of the lung. Br J Ind Med 1965;22:72-7.

20. Grayson CE, Blunmenfeld H. Egg-shell calcification in silicosis. Radiology 1949;53:216-26.

21. Ikeda T, Sasaki M, Yamada N, et al. Controlling air leaks using free pericardial fat pads as surgical sealant in pulmonary resection. Ann Thorac Surg 2015;99:1170-5.

22. Miyamoto H, Futagawa T, Wang Z, et al. Fibrin glue and bioabsorbable felt patch for intraoperative intractable air leaks. Jpn J Thorac Cardiovasc Surg 2003;51:232-6.

23. Rivera C, Bernard A, Falcoz PE, et al. Characterization and prediction of prolonged air leak after pulmonary resection: a nationwide study setting up the index of prolonged air leak. Ann Thorac Surg 2011;92:1062-8.

24. Suda T. Uniportal subxiphoid video-assisted thoracoscopic thymectomy. J Vis Surg 2016;2:123.

25. Yang $X$, Wang L, Zhang C, et al. The feasibility and advantages of subxiphoid uniportal video-assisted thoracoscopic surgery in pulmonary lobectomy. World J Surg 2019;43:1841-9.

26. Weigl M, Stefan P, Abhari K, et al. Intra-operative disruptions, surgeon's mental workload, and technical performance in a full-scale simulated procedure. Surg Endosc 2016;30:559-66.

27. Dias RD, Scalabrini Neto A. Acute stress in residents during emergency care: a study of personal and situational factors. Stress 2017;20:241-8.

28. Chen C, Zhang X, Gu C, et al. Surgery performed at night by continuously working surgeons contributes to a higher incidence of intraoperative complications in videoassisted thoracoscopic pulmonary resections: a large mono centric retrospective study. Eur J Cardiothorac Surg 2020; 57: 447-54.

29. Sonoda Y, Onozuka D, Hagihara A. Factors related to teamwork performance and stress of operating room nurses. J Nurs Manag 2018;26:66-73.

30. Kivimäki M, Jokela M, Nyberg ST, et al. Long working hours and risk of coronary heart disease and stroke: a systematic review and meta-analysis of published and unpublished data for 603,838 individuals. Lancet 2015;386:1739-46.

31. Lavander P, Meriläinen M, Turkki L. Working time use and division of labour amount nurses and health-care workers in hospitals - a systematic review. J Nurs Manag 2016;24:1027-40.

32. Park AE, Zahiri HR, Hallbeck MS, et al. Intraoperative "Micro Breaks" with targeted stretching enhance surgeon physical function and mental focus: a multicenter cohort study. Ann Surg 2017;265:340-6.

Cite this article as: Homma T, Shimada Y, Tanabe K, Akemoto Y, Ojima T, Yamamoto Y, Kitamura N, Yoshimura N. Adverse factors and postoperative neuropathic pain in challenging video-assisted thoracoscopic surgery. Ann Palliat Med 2021;10(3):2849-2858. doi: 10.21037/apm-20-1729 